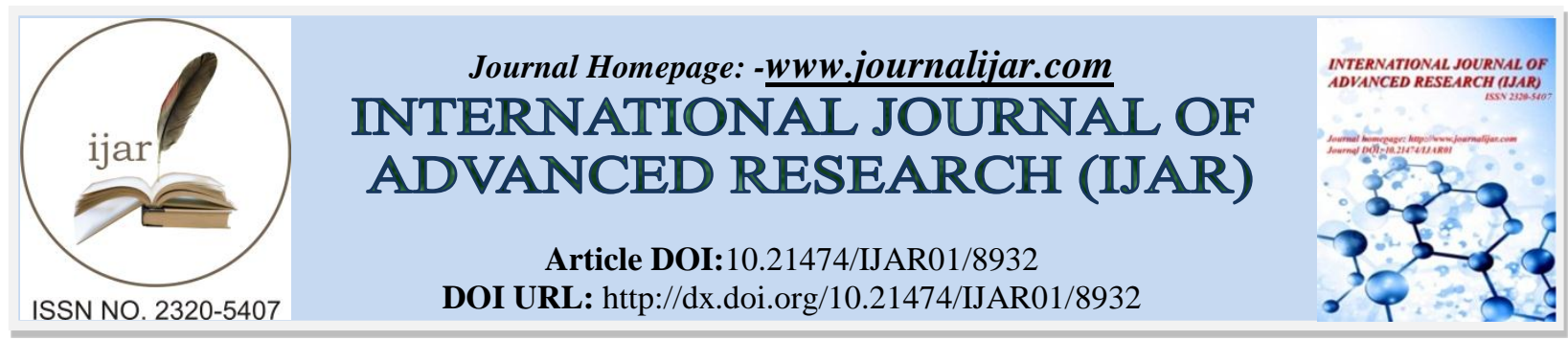

RESEARCH ARTICLE

\title{
COMPARISON BETWEEN THE EFFECT OF AMIODARONE AND LIDOCAINE WITH MAGNESIUM SULFATE ON OCCURRENCE OF REPERFUSION VENTRICULAR FIBRILLATION AFTER AORTIC CROSS CLAMP RELEASE ON AORTIC VALVE SURGERY.
}

Mohamed Abbas Mohamed, Hatem El Moutaz Mahmoud and Ahmed Mostafa El-Shaarawy. Anesthesiology, Surgical ICU and Pain management department, faculty of medicine, Beni-suef university, Egypt.

\section{Manuscript Info}

Manuscript History

Received: 22 February 2019

Final Accepted: 24 March 2019

Published: April 2019

Key words:-

Ventricular fibrillation, Aortic valve surgery, lidocaine, magnesium sulfate, amiodarone.

\section{Abstract}

Background:Reperfusion ventricular fibrillation (VF) after aortic cross-clamp (ACC) release is one of the most common complications after Aortic valve surgery.

Materials and methods:Eighty seven patients who had undergone Aortic valve surgery were assigned randomly to three groups (29 patients each). The lidocaine group received lidocaine with magnesium sulfate (mgso4) (100 mg lidocaine and $2 \mathrm{~g} \mathrm{mgso} 4)$ in $25 \mathrm{ml}$ isotonic saline, the amiodarone group received (300 $\mathrm{mg}$ amiodarone) diluted in $25 \mathrm{ml}$ of an isotonic saline, and the control group received $25 \mathrm{ml}$ normal saline by a pump circuit $3 \mathrm{~min}$ before ACC release. Anesthetic management, weaning protocol from cardiopulmonary bypass, were standardized. All the patients were monitored after the release of ACC and $\mathrm{VF}$ were recorded.

Results:Incidence of VF after release of ACC was lower in the lidocaine with mgso4 group compared with the amiodarone and control group [6 (20.7\%), 8 (27.6\%) vs. $12(41.4 \%)$ ] but there was no statistically significant difference between all groups $(P=0.215)$. Also, the incidence of an atrioventricular block and bradycardia after release ACC was higher in the lidocaine mgso4 group compared with the amiodarone and control groups [7 (24.1\%) vs. 4 (13.8\%) and 3 $(10.3 \%)$, respectively)] but there was no statistically significant difference between all groups $(P=0.331)$.

Conclusion:The administration of lidocaine with mgso4 before the release of ACC reduced the incidence of VF. However, the administration of Lidocaine with mgso4 was associated with more transient atrioventricular block.

Copy Right, IJAR, 2019,. All rights reserved.

\section{Introduction:-}

The occurrence of ventricular fibrillation (VF) after removal of the aortic cross-clamp in patients operating cardiovascular surgical procedure has been accounted for to be somewhere in the range of $45 \%$ and $100 \%$. (Samantaray et al., 2010)

Corresponding Author:-Mohamed Abbas Mohamed.

Address:-Anesthesiology, Surgical ICU and Pain management department, faculty of medicine, Beni-suef university, Egypt. 
Numerous mechanisms have been suggested to give an explanation for the elevated incidence of VF, as well as ischemia-mediated increases in reentry, automaticity, and reperfusion injury. (Kaplinsky et al., 1981)

VF may lead to greater than before myocardial oxygen consumption, enlargement of the ventricle with consequential wall tension increase, and myocardial tissue acidosis. (Lockerman et al., 1987) These changes may be especially obvious within the hypertrophied ventricle when the mean arterial blood pressure is lower than 50 to $60 \mathrm{~mm}$ hg. (Spadaro et al., 1982)

Despite the fact that VF is thought to adversely have an effect on the heart, the "gold standard" management is internal direct-current shock, which could be harmful. animal models using monophasic damped sine waveform shocks suggest that defibrillation leads to diminished myocardial performance and microscopic damage to myocytes as well as the injury is more obvious with frequent shocks with a short time between shocks. (Yamaguchi et al., 2002)

From these data, the prevention of reperfusion VF or a reduction in the defibrillation attempts needed to discontinue VF could be of advantage in saving myocardial function after cardiopulmonary bypass (CPB). lidocaine, a class IB (Na channel blocking) anti-arrhythmic medication, has a long history of use in cardiac surgical procedure for the prophylaxis of VF. many studies have demonstrated that its effectiveness in preventing VF and reducing the shocks needed to defibrillate VF. (Ayoub et al., 2009)

Intravenous amiodarone (class III antiarrhythmic drug) has many mechanisms of action, together with blockade of sodium, potassium, and calcium channels, moreover as beta and alpha-adrenergic antagonism. (Sarkozy \& Dorian, 2003)

Alternative studies have demonstrated amiodarone to enhance the VF response to shocks. (Petrovic et al.,1998) Two modern studies have weighted amiodarone for VF prophylaxis after aortic cross-clamping with mixed outcome. (Samantaray et al., 2010)

The goal of the present study was to evaluate whether amiodarone or lidocaine with magnesium sulfate was superior to placebo for the prevention of VF after aortic cross clamp removal in patients undergoing aortic valve surgery.

\section{Materials And Methods:-}

This randomized controlled trial study was conducted in Beni Suef university Hospital from 2/2016 to 2/2018 after approval by the internal ethical committee. Written informed consent was taken from all patients before the start.

Patients were eligible for inclusion if they were undergoing an elective aortic valve procedure that was expected to include cross clamping of the aorta. Patients excluded from the study who had history of treatment with digoxin, amiodarone, or lidocaine (including cardiopulmonary resuscitation). Also, patients had Contraindications to amiodarone (sick sinus syndrome, atrioventricular conduction abnormalities, thyroid disease, interstitial lung disorders, renal or liver disease, and known allergic or toxic reactions to amiodarone) or patients with Combined cardiac surgery and emergent operation.

Patients were randomly assigned to three groups in a 1:1:1 fashion. Group A received $300 \mathrm{mg}$ of amiodarone diluted with normal saline to $25 \mathrm{ml}$, group B received $5 \mathrm{ml}$ of lidocaine $2 \%(100 \mathrm{mg}$ ) and $2 \mathrm{~g}$ magnesium sulfate (25ml), and group C (control group) received $25 \mathrm{ml}$ normal saline by the way of pump circuit, 3 minutes before aortic cross clamp release. All study drugs were prepared by a research pharmacist and diluted to $25 \mathrm{~mL}$ total volume. Anesthesiologists, surgeons, and CPB perfusionists were strictly blinded as to the content of the syringes.

\section{Procedure}

Patients' baseline characteristics will include age, sex, weight and the patients' echocardiographic information included concomitant valve disease and left ventricular ejection fraction (LVEF). Standard clinical protocol was used for all patients. Complete blood count, a standard coagulation profile and electrolytes was performed a day before surgery.

All patients were monitored with pulse-oximeter, invasive blood pressure (IBP) device, central venous pressure (CVP), and electrocardiography (lead II toV5). Premedication was midazolam 2-3 mg one hour before surgery. 


\begin{tabular}{|l|l|l|l|l|}
\hline $\begin{array}{l}\text { Age } \\
\text { Mean } \pm \text { SD }\end{array}$ & $35.6 \pm 13.3$ & $36.7 \pm 14.8$ & $34.1 \pm 15.7$ & 0.801 \\
\hline $\begin{array}{l}\text { Gender (No \& \%) } \\
\text { Male }\end{array}$ & 19 & 19 & 22 & 0.617 \\
Female & 10 & 10 & 7 & 0.164 \\
\hline $\begin{array}{l}\text { Weight } \\
\text { Mean } \pm \text { SD }\end{array}$ & $79.3 \pm 12.2$ & $79.8 \pm 9.7$ & $84.5 \pm 11.8$ & 0.315 \\
\hline $\begin{array}{l}\text { Ejection fraction } \\
\text { Mean } \pm \text { SD }\end{array}$ & $59.1 \pm 8.4$ & $55.8 \pm 9.3$ & $58.2 \pm 7.6$ & 0.771 \\
\hline $\begin{array}{l}\text { Main Valve lesion (No } \\
\text { \&\%)Aortic stenosis } \\
\text { Aortic regurgitation }\end{array}$ & $\begin{array}{l}8(27.6) \\
21(72.4)\end{array}$ & $\begin{array}{l}6(20.7) \\
23(79.3)\end{array}$ & $\begin{array}{l}6(20.7) \\
23(79.3)\end{array}$ & \\
\hline
\end{tabular}

Data of Age, weight and ejection fraction presented as mean and standard deviation(SD) and of gender and main valve lesion as number and percentage

Table 2:-Comparison between the three groups regarding bypass criteria

\begin{tabular}{|l|l|c|c|c|}
\hline Criteria & Mean \pm SD & P-value & \multicolumn{2}{|c|}{ 95\% C.I for Mean } \\
\cline { 4 - 5 } & & & Lower Bound & Upper Bound \\
\hline ACC & & & & \\
Lidocaine & $142.8 \pm 49.2$ & 0.092 & 124.1 & 161.5 \\
Amiodarone & $133.1 \pm 19.4$ & & 113.7 & 140.5 \\
Control & $123.2 \pm 24.9$ & & & 132.6 \\
\hline CPB Time & & & 150.9 & 197.3 \\
Lidocaine & $174.1 \pm 60.9$ & 0.091 & 151.8 & 170.7 \\
Amiodarone & $161.3 \pm 24.8$ & & 139.1 & 160.9 \\
Control & $149.9 \pm 28.6$ & & 2033 & 2610 \\
\hline Cardioplegia volume & & & 2038 & 2298 \\
Lidocaine & $2322 \pm 752$ & 0.298 & 1941 & 2269 \\
Amiodarone & $2168 \pm 328$ & & & \\
Control & $2105 \pm 541$ & & 240.8 & 287 \\
\hline Length of operation & & & 247.6 & 269 \\
Lidocaine & $264 \pm 60$ & 0.392 & 236 & 261 \\
\hline Amiodarone & $258.6 \pm 28.9$ & & \\
Control & $248.5 \pm 32.9$ & &
\end{tabular}

Data presented as mean and standard deviation(SD)

Table 3:-Impact of using the lidocaine, amiodarone and saline on arrhythmia and need of DC shock

\begin{tabular}{|l|l|l|l|l|}
\hline \multirow{2}{*}{ Outcome } & \multicolumn{2}{c|}{ Groups } & \multirow{2}{*}{ P-value } \\
\cline { 2 - 4 } & $\begin{array}{l}\text { Lidocaine } \\
\text { (No \& \%) }\end{array}$ & $\begin{array}{l}\text { Amiodarone } \\
\text { (No \& \%) }\end{array}$ & $\begin{array}{l}\text { Control } \\
\text { (No \& \%) }\end{array}$ & \\
\hline $\begin{array}{l}\text { Incidence of VF after ACC } \\
\text { release }\end{array}$ & $6(20.7)$ & $8(27.6)$ & $12(41.4)$ & 0.215 \\
\hline $\begin{array}{l}\text { Incidence of Bradyarrhythmia or } \\
\text { Heart block }\end{array}$ & $7(24.1)$ & $4(13.8)$ & $3(10.3)$ & 0.331 \\
\hline $\begin{array}{l}\text { Need of DC shock } \\
\text { once } \\
\text { twice }\end{array}$ & $\begin{array}{l}4(13.8) \\
2(6.9)\end{array}$ & $\begin{array}{l}7(24.1) \\
1(3.4)\end{array}$ & $\begin{array}{l}10(34.5) \\
2(6.9)\end{array}$ & 0.421 \\
\hline $\begin{array}{l}\text { Amount of joules } \\
\text { Take 20 } \\
\text { Take 50 }\end{array}$ & $\begin{array}{l}4(13.8) \\
2(6.9)\end{array}$ & $\begin{array}{l}7(24.1) \\
1(3.4)\end{array}$ & $\begin{array}{l}10(34.5) \\
2(6.9)\end{array}$ & \\
\hline
\end{tabular}




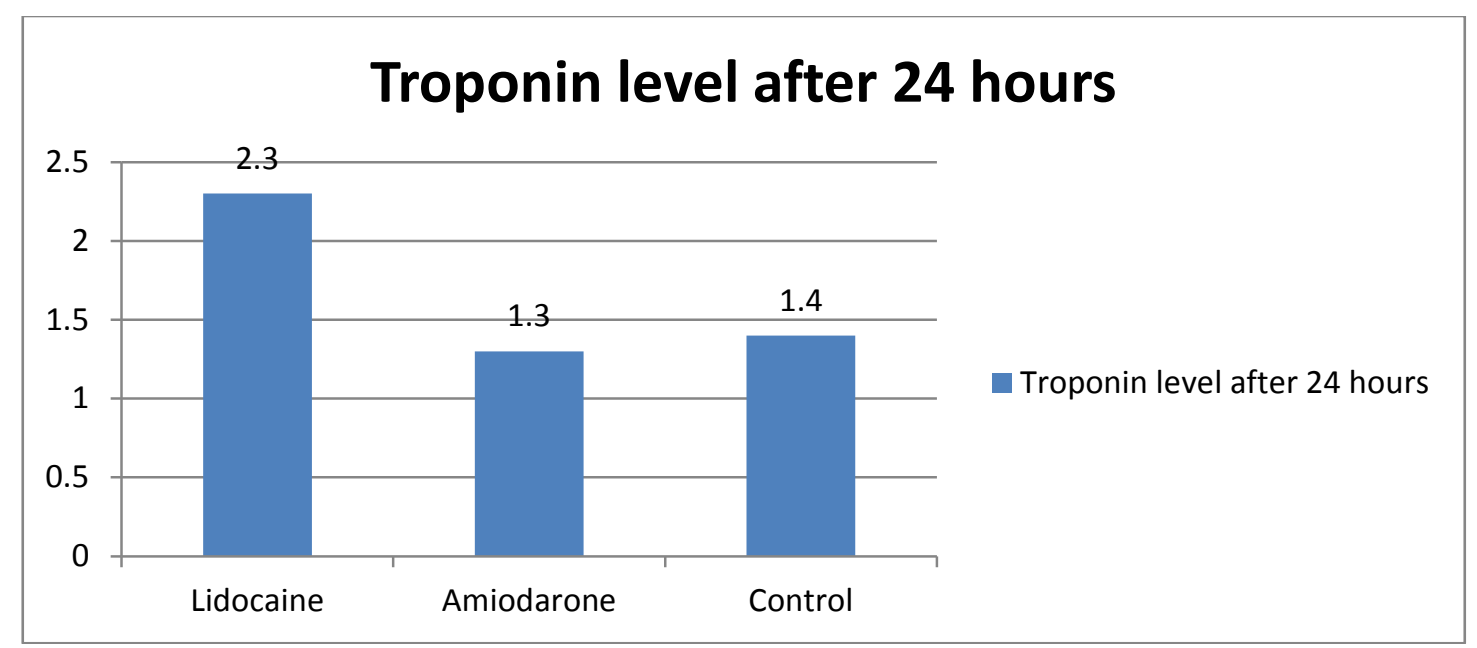

Figure 1:-Comparison between the three groups regarding troponin level after 24 hours

\section{Discussion:-}

In this trial of patients undergoing aortic valve procedures, neither amiodarone nor lidocaine given 3 minutes before aortic cross clamp removal decreased the incidence of VF. However, amiodarone, but not lidocaine, decreased the number of shocks required to terminate VF.

Many studies have shown lidocaine to decrease the reperfusion VF incidence when compared with control groups. (Ayoub et al., 2009)(Fall et al., 1987)(Praeger et al., 1988)(Samantaray et al., 2010)

All of these studies were performed in patients undergoing CABG. Thus, the current trial differs from these studies in that we included aortic procedures. Our study also was similar with two of previous studies and differed from other studies in terms of lidocaine dosing. Two of the previous studies used doses of $100 \mathrm{mg}$ of lidocaine similar to us , (Ayoub et al., 2009 (Baraka et al., 2000) two studies used doses of $200 \mathrm{mg}$ of lidocaine, (Praeger et al., 1988) (Samantaray et al., 2010) and one study administered $2 \mathrm{mg} / \mathrm{kg}$ of lidocaine. (Fall et al., 1987)

Praeger et al. showed that the incidence of VF was reduced to less than $33 \%$ with treatment with 200 mg of lidocaine intravenously 3 minutes before aortic cross clamp release. (Praeger et al., 1988)

Samantaray and colleagues randomized 34 patients undergoing CABG to receive $150 \mathrm{mg}$ of amiodarone or placebo before aortic cross clamp removal. The incidence of VF in the amiodarone group was $18 \%$ versus $65 \%$ in the placebo group $(\mathrm{P}=0.01)$. (Samantaray et al., 2010)

In a large trial, Ayoub and colleagues randomized 120 patients undergoing CABG to receive 150 mg amiodarone, $100 \mathrm{mg}$ lidocaine, or placebo 2 minutes before removal of the aortic cross clamp. They found that VF incidence was higher in the groups receiving amiodarone or placebo versus the group receiving lidocaine (48\% vs. $45 \%$ vs. $20 \%$ respectively, $\mathrm{P}=0.031)$. However, they found the energy required to terminate $\mathrm{VF}$ was lower in the patients receiving amiodarone versus the controls $(16 \pm 7 \mathrm{~J}$ vs. $25 \pm 8 \mathrm{~J}$; $\mathrm{P}=.023)$. (Ayoub et al., 2009)

The dose of amiodarone used in this study was significantly higher than the dose used in the two previous investigations $300 \mathrm{mg}$ vs $150 \mathrm{mg}$. This dose was selected according to the large volume of distribution of amiodarone and the expected hemodilution in the CPB reservoir. Even with this larger dose, it was unable to replicate the decrease in VF found by Samantaray and colleagues. (Samantaray et al., 2010)

Our results were similar to those of Ayoub and colleagues, who found no difference in the incidence of VF, but that VF was more easily terminated in patients receiving amiodarone. 29 patients who were taking amiodarone preoperatively had a decreased incidence of VF but not statistically significant and required fewer shocks to terminate VF but they suggest that an intravenous bolus of $300 \mathrm{mg}$ of amiodarone may not be adequate to achieve therapeutic tissue levels in the myocardium. Future studies aimed at preventing reperfusion VF may focus on preoperative loading of patients with oral amiodarone. 


\section{Study Limitations}

The current trial has some limitations. Despite enrolling a homogeneous surgical population. As noted earlier, the dose of administered amiodarone may not have been high enough to achieve therapeutic tissue levels given the added circulatory volume of the $\mathrm{CPB}$ circuit.

\section{Conclusions:-}

When applied to patients undergoing aortic valve surgical procedures, neither $300 \mathrm{mg}$ of amiodarone nor $1.5 \mathrm{mg} / \mathrm{kg}$ of lidocaine with $2 \mathrm{~g}$ of magnesium sulfate administered 3 minutes before aortic cross clamp removal decreases the incidence of VF. However, amiodarone, but not lidocaine, reduces the number of shocks required to terminate VF after aortic cross clamp removal.

\section{Conflict of interest}

None

\section{Acknowledgment:-}

Hazem Abd El Wahab (lecturer of anesthesiology, surgical ICU and pain management department, faculty of medicine, Beni-suef university, Egypt.) for his support and Encouraging.

\section{References:-}

1. Ayoub, C. M., Sfeir, P. M., Bou-Khalil, P., Azar, M., Ala'S, H., et al., (2009). Prophylactic amiodarone versus lidocaine for prevention of reperfusion ventricular fibrillation after release of aortic cross-clamp. European Journal of Anaesthesiology (EJA), 26(12), 1056-1060.

2. Baraka, A., Kawkabani, N., Dabbous, A., \& Nawfal, M. (2000). Lidocaine for prevention of reperfusion ventricular fibrillation after release of aortic cross-clamping. Journal of Cardiothoracic and Vascular Anesthesia, 14(5), 531-533.

3. Fall, S. M., Burton, N. A., Graeber, G. M., Head, H. D., Lough, F. C., et al., (1987). Prevention of ventricular fibrillation after myocardial revascularization. The Annals of Thoracic Surgery, 43(2), 182-184.

4. Kaplinsky, E., Ogawa, S., Michelson, E. L., \& Dreifus, L. S. (1981). Instantaneous and delayed ventricular arrhythmias after reperfusion of acutely ischemic myocardium: evidence for multiple mechanisms. Circulation, 63(2), 333-340.

5. Lockerman, Z. S., Rose, D. M., Cunningham, J. J. N., \& Lichstein, E. (1987). Reperfusion ventricular fibrillation during coronary artery bypass operations and its association with postoperative enzyme release. The Journal of Thoracic and Cardiovascular Surgery, 93(2), 247-252.

6. Petrovic, T., Adnet, F., \& Lapandry, C. (1998). Successful resuscitation of ventricular fibrillation after low-dose amiodarone. Annals of Emergency Medicine, 32(4), 518-519.

7. Praeger, P. I., Kay, R. H., Moggio, R., Somberg, E., Pooley, R., et al., (1988). Prevention of ventricular fibrillation after aortic declamping during cardiac surgery. Texas Heart Institute Journal, 15(2), 98.

8. Samantaray, A., Chandra, A., \& Panigrahi, S. (2010). Amiodarone for the prevention of reperfusion ventricular fibrillation. Journal of Cardiothoracic and Vascular Anesthesia, 24(2), 239-243.

9. Sarkozy, A., \& Dorian, P. (2003). Strategies for reversing shock-resistant ventricular fibrillation. Current Opinion in Critical Care, 9(3), 189-193.

10. Spadaro, J., Bing, O. H., Gaasch, W. H., Laraia, P., Franklin, A., et al., (1982). Effects of perfusion pressure on myocardial performance, metabolism, wall thickness, and compliance: comparison of the beating and fibrillating heart. The Journal of Thoracic and Cardiovascular Surgery, 84(3), 398-405.

11. Yamaguchi, H., Weil, M. H., Tang, W., Kamohara, T., Jin, X., et al., (2002). Myocardial dysfunction after electrical defibrillation. Resuscitation, 54(3), 289-296. 